\title{
Prognostic value of cardiopulmonary exercise testing in patients with systemic sclerosis
}

\author{
Ralf Ewert ${ }^{1}$, Till Ittermann², Dirk Habedank ${ }^{3^{*}}$ (D), Matthias Held ${ }^{4}$, Tobias J. Lange ${ }^{5}$, Michael Halank ${ }^{6}$, Jörg Winkler ${ }^{7}$, \\ Sven Gläser ${ }^{8}$, Horst Olschewski ${ }^{9,10}$ and Gabor Kovacs ${ }^{9,10}$
}

\begin{abstract}
Background: Systemic sclerosis (SSc) is a severe rheumatic disease of the interstitial tissue, in which heart and lung involvement can lead to disease-specific mortality. Our study tests the hypothesis that in addition to established prognostic factors, cardiopulmonary exercise testing (CPET) parameters, particularly peak oxygen uptake (peakVO ${ }_{2}$ ) and ventilation/carbon dioxide $(\mathrm{VENCO})$-slope, can predict survival in patients with SSc.

Subjects and methods: We retrospectively assessed 210 patients ( $80.9 \%$ female) in 6 centres over 10 years with pulmonary testing and CPET. Survival was analysed with Cox regression analysis (adjusted for age and gender) by age, comorbidity (Charlson-Index), body weight, body-mass index, extensive interstitial lung disease, pulmonary artery pressure (measured by echocardiography and invasively), and haemodynamic, pulmonary and CPET parameters.

Results: Five- and ten-year survival of SSc patients was 93.8 and 86.9\%, respectively. There was no difference in survival between patients with diffuse (dcSSc) and limited cutaneous manifestation (IcSSc; $p=0.3$ ). Pulmonary and CPET parameters were significantly impaired. Prognosis was worst for patients with pulmonary hypertension $(p=$ 0.007), 6-min walking distance $<413 \mathrm{~m}(p=0.003)$, peakVO ${ }_{2}<15.6 \mathrm{~mL} \cdot \mathrm{kg}^{-1} \cdot \mathrm{min}^{-1}$, and $\mathrm{VENCO}{ }_{2}$-slope $>35$. Age (hazard ratio $H R=1.23 ; 95 \%$ confidence interval $\mathrm{Cl}: 1.14 ; 1.41)$, VENCO ${ }_{2}$-slope $(H R=0.9 ; \mathrm{Cl} 0.82 ; 0.98)$, diffusion capacity (Krogh factor, $\mathrm{HR}=0.92 ; \mathrm{Cl} 0.86 ; 0.98)$, forced vital capacity (FVC, $\mathrm{HR}=0.91 ; \mathrm{Cl} 0.86 ; 0.96)$, and peakVO $(\mathrm{HR}=$ 0.87; Cl 0.81;0.94) were significantly linked to survival in multivariate analyses (Harrell's $C=0.95$ ).

Summary: This is the first large study with SSc patients that demonstrates the prognostic value of peakVO $\mathrm{O}_{2}<15.6$ $\mathrm{mL} \cdot \mathrm{kg}^{-1} \cdot \mathrm{min}^{-1}\left(<64.5 \%\right.$ of predicted peakVO $\left.\mathrm{N}_{2}\right)$ and $\mathrm{VEN} \mathrm{NCO}_{2}$-slope $>35$.
\end{abstract}

Keywords: Systemic sclerosis, Cardiopulmonary exercise, Pulmonary function, Prognosis, Pulmonary hypertension

\section{Background}

Systemic sclerosis (SSc) is a severe inflammatory disease of the interstitial tissue with clinical manifestations ranging from limited skin involvement to life-threatening effects on the heart, kidneys and lungs. SSc is a rare disease with an annual incidence in Europe of about 2 cases per 100,000 population, and a prevalence of about $10-25$ per 100,000 $[1,2]$. According to international registry studies [3], a high proportion of patients with SSc have interstitial lung disease (ILD), with or without pulmonary hypertension (PH),

\footnotetext{
* Correspondence: d.habedank@drk-kliniken-berlin.de

${ }^{3}$ Department of Cardiology, DRK Kliniken Berlin, Berlin, Germany

Full list of author information is available at the end of the article
}

cardiac and gastrointestinal involvement. Cardiac, pulmonary and renal manifestations of SSc lead to an elevated disease-specific mortality [4-6]. Despite therapeutic progress, the mortality of patients with SSc is 3.5-fold higher than that of the general population - this factor has been stable over several decades [7].

Involvement of internal organs and joints typically results in impairment of exercise capacity, as measured by the 6min-walk test (6-MWT) or cardiopulmonary exercise testing (CPET). In particular, CPET provides an important insight into exercise physiology, and has shown patients with SSc to have a lower cardiopulmonary exercise capacity, measured as peak oxygen uptake (peakVO $\mathrm{VO}_{2}[8]$ and

(c) The Author(s). 2019 Open Access This article is distributed under the terms of the Creative Commons Attribution 4.0 International License (http://creativecommons.org/licenses/by/4.0/), which permits unrestricted use, distribution, and reproduction in any medium, provided you give appropriate credit to the original author(s) and the source, provide a link to the Creative Commons license, and indicate if changes were made. The Creative Commons Public Domain Dedication waiver (http://creativecommons.org/publicdomain/zero/1.0/) applies to the data made available in this article, unless otherwise stated. 
as the relationship between ventilation and carbon dioxide output (VE/ $/ \mathrm{VCO}_{2}$-slope) [9], compared with control individuals. Recent studies suggest that CPET can be used to determine whether the primary cause of exercise capacity limitation is cardiac or pulmonary in origin [10,11]. Prognosis in SSc has not previously been assessed using CPET. However, studies in PH [12] and pulmonary arterial hypertension (PAH) [13] that included patients with SSc as a subgroup have suggested that CPET parameters may have prognostic value.

Against this background, we retrospectively assessed CPET parameters which could potentially predict survival. Analysis of a representative number of patients with SSc was made possible through the collaboration of multiple centres. Patients with SSc were subdivided into groups with and without interstitial pulmonary manifestations. We hypothesised that in addition to established prognostic factors - age, PH and ILD - CPET parameters, particularly peakVO $\mathrm{VO}_{2}$ and $\mathrm{VE} / \mathrm{VCO}_{2}$-slope, can predict survival in patients with SSc.

\section{Methods}

\section{Study design and participants}

This study was a retrospective analysis of patients with SSc from a prevalent cohort. The patients were treated in four university hospitals (Greifswald, Regensburg, Dresden and Graz) and two expert centres (Missio Clinic Würzburg, and the Leipzig Pulmonary Study Center). All patients fulfilled the criteria of SSc or CREST syndrome (Calcinosis, Raynaud's syndrome, Oesophageal dysmotility, Sclerodactyly, Telangiectasia; a subgroup of SSc with limited cutaneous manifestation [lcSSc]) according to current guidelines [14].

Patients without CPET data were excluded from the analysis, as were those with pulmonary diseases other than SSc (e.g. bronchial asthma, previous pulmonary surgery, or pulmonary emphysema visible in highresolution computed tomography [HR-CT]). Patients with impaired systolic left ventricular function or relevant valvular disease other than tricuspid regurgitation (TR) were also excluded.

Patients with SSc were divided into two groups. Group 1 comprised patients with diffuse cutaneous SSc (dcSSc, $n=88$ ). Group 2 (lcSSc, $n=122$ ) included patients with lcSSc (including a subgroup presenting as CREST syndrome, $n=51$ ). Pulmonary manifestation was assessed by HR-CT and pulmonary function testing as defined by the American College of Rheumatology/European League Against Rheumatism criteria [15]. Parenchyma involvement $<20 \%$ was considered to represent a limited manifestation. Extensive manifestation was defined as $\geq 20 \%$ parenchyma involvement. Patients with an uncertain extent of manifestation according to HR-CT were classified as extensive manifestation if forced vital capacity (FVC; as percentage of predicted [\%predicted]) was $<70 \%$ of normal [16]. Co-morbidity was assessed using the Charlson index [17].

Follow-up and survival of all patients was documented from the first visit until June 30, 2016 (December 31, 2014 at Graz). Patients whose survival could not be documented at these dates were censored at the last day of contact. We defined three different follow-up times: 1) at time of diagnosis for the comparison between dcSSc and lcSSc (groups 1 and 2) and for demographic data such as age and gender; 2) at time of CPET for all other analyses except right heart catheterization (RHC) data; and 3) at time of RHC for analysis of the prognostic value of systolic right ventricular pressure $\left(R V_{\text {sys }}\right)$.

\section{Echocardiography}

Resting echocardiography was performed by experienced physicians according to relevant guidelines [18, 19]. TR was classified according to American College of Cardiology/European Society of Cardiology (ESC) recommendations, and $R V_{\text {sys }}$ was estimated by simplified Bernoulli equation via TR velocity $(v)$ as $\mathrm{RV}_{\text {sys }}(\mathrm{mmHg})=4 v^{2}$, with the addition of $5 \mathrm{mmHg}$ if the inferior vena cava was not dilated and there was visible respiratory variability, and $10 \mathrm{mmHg}$ if the inferior vena cava was dilated or without respiratory variability.

\section{Pulmonary function and diffusion capacity}

All centres assessed pulmonary function by spirometry, body plethysmography and measurement of diffusion capacity according to current standards [20-22]. Obstructive pulmonary disease was defined by forced expiratory volume in 1 second (FEV1)/FVC <70\%; restrictive pulmonary disease by total lung capacity (TLC) $<80 \%$; and clinically relevant diffusion impairment by diffusion capacity of carbon monoxide (DLCO) $<60 \%$ of normal. Normal values for FEV1, FVC and TLC were calculated by the formulas published by our working group [23-25], and normal values for DLCO were taken from European Respiratory Society (ERS) formulas [26].

\section{Cardiopulmonary exercise testing}

CPET was performed on a bicycle ergometer as a symptom-limited test. Performance and analysis methods have been described in detail previously [23, 27]. All centres started the test with a 3-min resting phase and unloaded cycling of 1-3 min (no unloaded phase was used at Graz), followed by a ramp protocol with $10-12.5$ $\mathrm{W} \cdot \mathrm{min}^{-1}$ in two centres and a step-increment protocol with $12.5-16 \mathrm{~W} \cdot \mathrm{min}^{-1}$ in the other centres. All values were recorded as absolute values and percentage of normal, based on our reference values [23]. 
The 6-MWT was performed according to current American Thoracic Society guidelines [28].

\section{Right heart catheterisation}

RHC was performed according to the guidelines of the ESC and the ERS [29] if clinical symptoms and echocardiographic criteria suggested possible $\mathrm{PH}$. We applied the criteria defined in an expert consensus [30], which are based on clinical findings (progressive or unexplained dyspnoea, signs of right heart failure), echocardiography ( $\mathrm{RV}_{\text {sys }}>45 \mathrm{mmHg}$, right ventricular dilation) and DLCO $(<50 \%)$. All centres used the mid-thoracic level as the zero-pressure point. PH was defined according to ESC and ERS guidelines as mean pulmonary artery pressure $\left(\mathrm{PAP}_{\text {mean }}\right) \geq 25 \mathrm{mmHg}$, and $\mathrm{PAH}$ was defined as $\mathrm{PAP}_{\text {mean }} \geq 25 \mathrm{mmHg}$, pulmonary artery wedge pressure (PAWP) $\leq 15 \mathrm{mmHg}$ and pulmonary vascular resistance (PVR) $>3$ Wood units $\left(>240 \mathrm{dyn} \cdot \mathrm{s} \cdot \mathrm{cm}^{-5}\right)$ [31].

\section{Statistical analysis}

Continuous variables, stratified by group status, are reported as median and interquartile range (IQR, in brackets). Categorical variables are reported as absolute numbers and percentages. Differences among groups were verified by Wilcoxon (continuous data) and $x^{2}$-tests (categorical data). Potential associations of group status and parameters from pulmonary function testing and CPET with mortality were tested using Cox regression models adjusted for age and gender. For group status the follow-up time was calculated based on the time of diagnosis; for the other variables the time of first examination defined the starting point.

Prediction models were determined using Cox regression models with age, gender, body mass index (BMI), and all parameters from pulmonary function testing and CPET as explanatory variables. For the final model, we eliminated variables by a backward selection procedure using a cut-off $p$-value of 0.1 . The discrimination of these models was reported by Harrell's C-statistic. Based on logistic regression models with the outcome "death: yes/no" we conducted receiver operating characteristic (ROC) analyses for selected variables. Kaplan-Meier curves were plotted for selected variables - for continuous variables, cut-off values were defined as the point which maximised the Youden index for the outcome "death". The Youden index is defined as sensitivity + specificity -1 .

All analyses were carried out with Stata 14.1 (Stata Corporation, College Station, TX, USA).

\section{Ethical approval}

The study was approved by the ethics committee of Greifswald University (No. 043/13a, study protocol and amendment of May 5th, 2015).

\section{Results}

The study included 210 patients with SSc - demographic and clinical data are shown in Table 1. The majority of patients were women in both SSc groups, with group 2 (dcSSc) having a significantly lower proportion of women $(73.9 \%)$ than group 1 (lcSSc, $86.1 \% ; p=0.03$ ). The proportion of active smokers was $<20 \%$ in both SSc groups. There were no significant differences between SSc groups in co-morbidity status (Charlson index: 2 [IQR, 1-2] in both groups; $p=0.65$ ) or in the proportion of patients with TR, assessed by echocardiography $(80.3$ vs $89.7 \% ; p=0.63$ ). A significantly higher proportion of patients in group 1 had extensive ILD, compared with group $2(27.1 \%$ vs $8.2 \% ; p<0.001)$.

Pulmonary function parameters were significantly different between SSc groups, particularly with regard to FEV1\%predicted (group 1, 90\% [IQR, 77-104\%]; group 2 , 95\% [IQR, 84-107\%; $p=0.002]$ ), and the proportion of patients with impaired FVC $(<70 \%$ of normal, $20.0 \%$ vs $8.6 \% ; p=0.02$ ). There were no significant differences in diffusion parameters (DLCO \%predicted and DLCO per alveolar volume [Krogh factor; KCO] \%predicted; Table 2), or the proportion of patients with DLCO \%predicted $\leq 60 \%$ ( $50.6 \%$ vs $37.8 \% ; p=0.08)$.

6-min-walking distance (6-MWD) was documented in 96 of 210 patients with SSc, with no significant difference between groups $(p=0.8)$. All CPET parameters tested were similar in the two SSc groups (e.g. peakVO $72.2 \%$ vs $75.2 \%$ of predicted; $p=0.3$ and VE/VCO2slope, 31.6 vs 33.6; $p=0.1$ ). The overall correlation of 6 MWD and peakVO $\mathrm{VO}_{2}$ was weak $(\mathrm{r}=0.2)$.

\section{Subgroup with right heart catheterisation}

RHC data were available for 136 patients, of whom 52 had $\mathrm{PH}$, including a subgroup of 38 patients with $\mathrm{PAH}$. Patients with lcSSC more frequently underwent RHC (73.8\% in group 1 vs $55.7 \%$ in group 2; $p=0.006$ ). There were no significant differences between SSc groups in the proportion of patients with $\mathrm{PH}$ (42.6 vs $36.0 ; p=0.45)$ or $\mathrm{PAH}(27.7 \%$ vs $28.7 \%$; $p=$ 0.9 ), or in haemodynamic parameters (Table 2). The subgroup with RHC had higher proportions of patients with extensive ILD and TR, higher mean estimated $\mathrm{RV}_{\text {sys }}$, and lower mean DLCO, FVC and 6-MWD. Most CPET parameters in the RHC group were worse compared with the non-RHC group (e.g. VE/ $/ \mathrm{VCO}_{2}$-slope, 35 [IQR, 29-47] vs 29 (IQR, 26-33); peakVO, 1087 (IQR, 824-1380) vs 1270 (IQR, 1097-1292) $\mathrm{mL} \cdot \mathrm{min}^{-1}$; both $p<0.001$; see Additional file 1: Table S1).

\section{Subgroup with interstitial lung disease}

All 195 patients with interpretable HR-CT were included in the subgroup analysis of pulmonary manifestation; of these, 191 patients had a complete pulmonary function test. The proportion of women was lower among patients with ILD (104 of 121; 86\%) than among those 
Table 1 Demographic parameters

\begin{tabular}{|c|c|c|c|c|}
\hline Parameter & $\mathrm{N}$ & Group 1 deSSc & Group 2 IcSSC & p-value (group 1 vs. 2) \\
\hline & & $\mathrm{n}=88$ & $n=122$ & \\
\hline Age (years) & 210 & $60(51 ; 70)$ & $62(52 ; 70.2)$ & 0.263 \\
\hline Female $(n)$ & 210 & $65(73.9 \%)$ & $105(86.1 \%)$ & 0.026 \\
\hline Time from first diagnosis to first visit at study centre (years) & 203 & $4(1 ; 7)$ & $4(1 ; 9)$ & 0.471 \\
\hline Never-smoker (n) & 137 & $57(68.7 \%)$ & $77(70.6 \%)$ & \\
\hline Ex-smoker (n) & 25 & $14(16.9 \%)$ & $11(10.1 \%)$ & \\
\hline Smoker $(n)$ & 33 & $12(14.5 \%)$ & $21(19.3 \%)$ & 0.313 \\
\hline Charlson index & 199 & $2(1 ; 2)$ & $1(1 ; 2)$ & 0.653 \\
\hline Height (cm) & 210 & $165(160 ; 175)$ & $165(160 ; 170)$ & 0.943 \\
\hline Weight (kg) & 210 & $71(62 ; 85)$ & $70(62 ; 77)$ & 0.206 \\
\hline BMI $\left(\mathrm{kg} \cdot \mathrm{m}^{-2}\right)$ & 210 & $25.7(23.0 ; 27.7)$ & $24.8(22.7 ; 28.4)$ & 0.162 \\
\hline Limited ILD (n) & 42 & 25 (29.4\%) & 17 (15.5\%) & \\
\hline Extensive ILD (n) & 32 & $23(27.1 \%)$ & $9(8.2 \%)$ & $<0.001$ \\
\hline
\end{tabular}

Data are presented as median (IQR) or $\mathrm{n}(\%)$

$B M I$ Body mass index, ILD Interstitial lung disease, IQR Interquartile range, dcSSC disseminated cutaneous manifestation, ICSSC limited cutaneous manifestation

without ILD (52 of 74; 74\%, $p<0.01$ ). Compared with patients without ILD, those with ILD had worse results in all pulmonary restriction and diffusion parameters, and more frequently underwent RHC. In addition, a higher proportion of patients with ILD had pulmonary limitation at exercise (defined as VE/MVV $>80 \%$ ). There were no significant differences in co-morbidity or echocardiography, or in most haemodynamic and CPET parameters. A detailed comparison between patients with and without ILD is shown in Additional file 2: Table S2.

\section{Mortality}

The median follow-up after first diagnosis of SSc was 7.7 years, with a total of 1970 patient-years analysed. From first diagnosis, 5-year survival was $93.8 \%$, and 10 -year survival was $86.9 \%$ (Fig. 1a). There was no significant difference in survival between SSc groups ( $p=0.3$; Fig. 1b). In addition, there was no significant difference in survival between patients without ILD and those with extensive ILD $(p=0.1)$ or limited ILD $(p=0.25)$. In the subgroup of patients with RHC $(n=139)$, for whom analysis of $\mathrm{PH}$ was possible, a diagnosis of $\mathrm{PH}$ was associated with a significantly worse prognosis $(p=0.007$, Fig. $1 \mathrm{~d})$.

\section{Prognostic factors}

Cox regression analysis adjusted for age and gender determined that a number of factors were significantly associated with mortality (Table 3). Prognostic value was identified for age, Charlson index, body weight, BMI, extensive ILD, echocardiographic $\mathrm{RV}_{\text {sys }}$, and various haemodynamic parameters, pulmonary function and CPET. Moreover, 6-MWD was significantly associated with survival, with a walking distance of $413 \mathrm{~m}$ discriminating best $(p=0.003$; Fig. 1c) between a favourable and a poor prognosis.

In a further step, the model was adjusted for BMI, age and gender and used to analyse all parameters of pulmonary function and CPET that had a significant association with survival (Table 4, model 1 ). In addition to age, in this model $\mathrm{FVC}, \mathrm{KCO}$ and peakVO 2 in $\mathrm{mL} \cdot \mathrm{kg}^{-1} \cdot \mathrm{min}^{-1}$ were significantly linked to survival (Harrel's $C, 0.96$ ). Exclusion of peak $\mathrm{VO}_{2}$ impaired the predictive value of the model (Harrel's C, 0.84). In a calculation restricted to KCO, TLC and peak $\mathrm{VO}_{2}$, only peakVO 2 remained associated with survival. A second model used peak $\mathrm{VO}_{2} \%$ predicted as a variable instead of peakVO 2 in $\mathrm{mL} \cdot \mathrm{kg}^{-1} \cdot \mathrm{min}^{-1}$ : in this model, age, $\mathrm{VE} / \mathrm{VCO}_{2}$-slope, $\mathrm{KCO}, \mathrm{FVC}$, and peak $\mathrm{VO}_{2} \%$ predicted had a significant association with survival (Table 4, model 2).

Finally, ROC analyses were conducted for the parameters peakVO 2 and $\mathrm{VE} / \mathrm{VCO}_{2}$-slope, and cut-off values were calculated (Fig. 2d). A peakVO $\mathrm{V}_{2}$ of $15.6 \mathrm{~mL} \cdot \mathrm{kg}^{-1} \cdot \mathrm{min}^{-1}$ (64.5\% of predicted) and a VE/ $\mathrm{VCO}_{2}$-slope of 34.9 had the highest discriminative value between favourable and poor prognoses (Fig. 2a-c).

\section{Discussion}

The results of this study demonstrate for the first time in a large cohort of patients with SSc that CPET parameters (peakVO $\mathrm{VO}_{2}, \mathrm{VE} / \mathrm{VCO}_{2}$-slope) and 6-MWD can predict survival.

Although there is some variation among previous studies (as detailed in Additional file 3: Table S3), these have in general found that peakVO${ }_{2}$, oxygen uptake at the anaerobic threshold $\left(\mathrm{VO}_{2} @ \mathrm{AT}\right)$ and the ratio of oxygen uptake to heart rate $\left(\mathrm{VO}_{2} / \mathrm{HR}\right)$ are lower in patients with $\mathrm{SSc}$ than reference or matched control values, while the ratio of ventilation to carbon dioxide output at the anaerobic 
Table 2 Hemodynamic, pulmonary function and CPET parameters

\begin{tabular}{|c|c|c|c|c|}
\hline Parameter & $\mathrm{N}$ & Group 1 dcSSc, $n=88$ & Group 2 lcSSc, n = 122 & p-value (group 1 vs. 2) \\
\hline Echocardiography available (n) & 192 & $80(90.9 \%)$ & $112(91.8 \%)$ & 0.819 \\
\hline TR detected (n) & 169 & 65 (80.3\%) & $104(89.7 \%)$ & 0.063 \\
\hline Estimated $\mathrm{RV}_{\text {sys }}(\mathrm{mmHg})$ & 159 & $31(25 ; 38)$ & $32(25 ; 45)$ & 0.498 \\
\hline Right heart catheter available (n) & 139 & 49 (55.7\%) & $90(73.8 \%)$ & 0.006 \\
\hline $\mathrm{RAP}_{\text {mean }}(\mathrm{mmHg})$ & 135 & $5(2 ; 7)$ & $5(3 ; 7)$ & 0.653 \\
\hline $\mathrm{PAP}_{\text {mean }}(\mathrm{mmHg})$ & 136 & $23(16 ; 33)$ & $21(15 ; 30)$ & 0.161 \\
\hline $\mathrm{PAP}_{\text {mean }} \geq 25 \mathrm{mmHg}$ & 136 & $20(42.6 \%)$ & $32(36.0 \%)$ & 0.451 \\
\hline PAWP (mmHg) & 136 & $9(5 ; 13)$ & $7(6 ; 10)$ & 0.059 \\
\hline PVR (Wood units) & 134 & $2.68(1.62 ; 5.34)$ & $2.17(1.49 ; 4.94)$ & 0.587 \\
\hline Cardiac output $\left(L \cdot \mathrm{min}^{-1}\right)$ & 123 & $5.17(4.40 ; 5.93)$ & $4.94(4.22 ; 5.88)$ & 0.251 \\
\hline $\mathrm{PAH}(\mathrm{n})$ & 134 & $13(27.7 \%)$ & $25(28.7 \%)$ & 0.895 \\
\hline TLC (\% predicted) & 205 & $93.8(79.0 ; 107.0)$ & $103.6(90.9 ; 115.9)$ & 0.026 \\
\hline VC (\% predicted) & 206 & $85.2(75.8 ; 102.0)$ & $100.5(83.3 ; 109.0)$ & 0.005 \\
\hline FVC (\% predicted) & 201 & $87(75 ; 105)$ & $97(84 ; 110)$ & 0.037 \\
\hline Proportion of patients with FVC $\leq 70 \%$ predicted & 201 & $17(20.0 \%)$ & $10(8.6 \%)$ & 0.019 \\
\hline FEV1 (\% predicted) & 206 & $90(77 ; 104)$ & $95(84 ; 107)$ & 0.002 \\
\hline FEV1/FVC (\%) & 204 & $83(78 ; 90)$ & $79(74 ; 86)$ & 0.571 \\
\hline RV (\% predicted) & 204 & $104(84 ; 124)$ & $114(95 ; 138)$ & 0.468 \\
\hline RV/TLC (\% predicted) & 194 & $105,1(92,6 ; 122,2)$ & $99,1(87,1 ; 111,7)$ & 0.110 \\
\hline DLCO (\% predicted) & 190 & $60(43 ; 77)$ & $68(45 ; 84)$ & 0.616 \\
\hline Proportion of patients with DLCO $\leq 60 \%$ predicted & 190 & $40(50.6 \%)$ & $42(37.8 \%)$ & 0.079 \\
\hline KCO (\% predicted) & 191 & $74.0(56.6 ; 89.2)$ & $71.8(59.8 ; 86.3)$ & 0.616 \\
\hline FVC (\% pred.)/DLCO (\% pred.) & 185 & $1.48(1.22 ; 1.94)$ & $1.42(1.22 ; 1.96)$ & 0.719 \\
\hline 6-MWD (m) & 96 & $447(372 ; 525)$ & $423(370 ; 478)$ & 0.798 \\
\hline Maximum power (Watts) & 209 & $84(68 ; 100)$ & $84(68 ; 116)$ & 0.723 \\
\hline Maximum power (\% predicted) & 209 & $87(62 ; 117)$ & $97(75 ; 118)$ & 0.180 \\
\hline $\mathrm{VO}_{2} @ \mathrm{AT}$ in \% of peakVO 2 predicted & 197 & $41.5(31.8 ; 55.8)$ & $41.0(35.3 ; 47.1)$ & 0.726 \\
\hline peakVO $2\left(\mathrm{~mL} \cdot \mathrm{min}^{-1}\right)$ & 210 & $1171(947 ; 1416)$ & $1180(899 ; 1476)$ & 0.780 \\
\hline peakVO $_{2}$ (\% of predicted) & 210 & $72.2(58.4 ; 84.6)$ & $75.2(58.3 ; 90.0)$ & 0.263 \\
\hline peakVO $2 /$ peakHR (L) & 207 & $9.1(7.2 ; 11.0)$ & $9.0(6.9 ; 10.8)$ & 0.953 \\
\hline VENCO ${ }_{2}$-slope & 200 & $31.6(27.0 ; 40.0)$ & $33.6(28.0 ; 42.0)$ & 0.117 \\
\hline VENCO & 208 & $37(32 ; 45)$ & $38(32 ; 43)$ & 0.726 \\
\hline VENCO $@$ AT & 206 & $32(29 ; 40)$ & $34(29 ; 42)$ & 0.121 \\
\hline pet $\mathrm{CO}_{2} @$ rest & 205 & $30.8(27.5 ; 34.0)$ & $30.8(26.5 ; 34.0)$ & 0.953 \\
\hline $\mathrm{pet}_{\mathrm{et}} \mathrm{CO}_{2} @ \mathrm{AT}$ & 203 & $33.8(29.8 ; 38.0)$ & $33.0(28.0 ; 37.9)$ & 0.291 \\
\hline VE/MW (\%) & 210 & $54.1(43.5 ; 68.1)$ & $55.2(44.8 ; 63.4)$ & 0.780 \\
\hline Proportion of VE/MW > 80\% (n) & 210 & $9(10.2 \%)$ & $11(9.0 \%)$ & 0.768 \\
\hline
\end{tabular}

Data are presented as median (IQR) or $\mathrm{n}(\%)$

6-MWD walking distance in $6 \mathrm{~min}$, CPET Cardiopulmonary exercise testing, DLCO Diffusion capacity of carbon monoxide, FEV1 Forced expiratory volume in 1 second, FVC Forced vital capacity, IQR Interquartile range, KCO Krogh factor (DLCO per alveolar volume), ICSSC limited cutaneous manifestation, PAH Pulmonary arterial hypertension, $P A P_{\text {mean }}$ mean pulmonary arterial pressure (by right heart catheter); $R V_{s y s}$ Systolic pulmonary arterial pressure (by echocardiography), $P A W P$ Pulmonary artery wedge pressure, peakVO ${ }_{2}$ peak oxygen uptake, $p_{e t} \mathrm{CO}_{2}$ End tidal pressure of carbon dioxide, $p_{e t} \mathrm{CO}_{2} @ A T$ End tidal pressure of carbon dioxide at anaerobic threshold, $P V R$ Pulmonary vascular resistance, $R A P_{\text {mean }}$ mean right atrial pressure, $R V$ Residual volume, $T L C$ Total lung capacity, $T R$ Tricuspid regurgitation, VC Vital capacity, VE/MVV Ratio of ventilation to maximum voluntary ventilation, VENCOO @ @AT Ratio of ventilation to carbon dioxide output at anaerobic threshold, VENCO @rest Ratio of ventilation to carbon dioxide output at rest, VEN $\mathrm{CO}_{2}$-slope Slope of the relation between ventilation and carbon dioxide output, $V O_{2} @ A T$ Oxygen uptake at anaerobic threshold, $V_{2} / H R$ Ratio of oxygen uptake to heart rate 

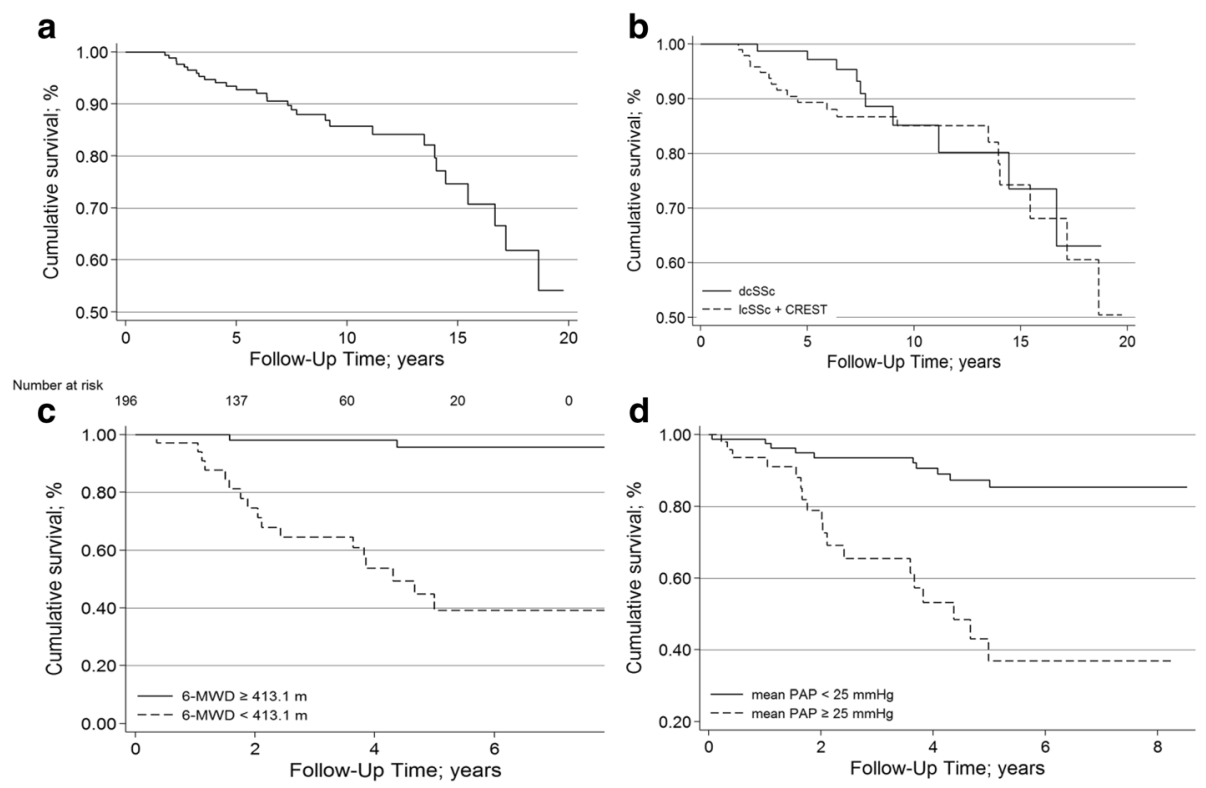

Fig. 1 Survival of patients after first diagnosis of SSC (Kaplan-Meier analyses). a Overall. b According to limited or disseminated disease. Bold line: group 1 (dcSSc, $n=88$ ); dashed line: group 2 ( $n=122$ ) comprising IcSSC $(n=71)$ and CREST-syndrome ( $n=51)$. c Divided by 6-MWD, Youden index defining best cut-off at $413 \mathrm{~m}$. d Divided by pulmonary hypertension. Bold line: PAPmean $\geq 25 \mathrm{mmHg}$, dashed line: PAPmean <25mmHg. 6-MWD: 6 minute walking distance; CREST: Calcinosis, Raynaud's syndrome, Oesophageal dysmotility, Sclerodactyly, Telangiectasia; dcSSc: disseminated cutaneous manifestation; ICSSC: limited cutaneous manifestation; PAPmean: mean pulmonary arterial pressure

threshold (VE/VCO $@$ @AT) is higher [8, 9, 11,32-37]. Our study confirmed these differences from reference values for pulmonary function, diffusion and CPET parameters.

The 5-year and 10-year survival rates from first diagnosis in our retrospective group of 210 patients with SSc were 93.8 and $86.9 \%$, respectively. Overall, patients in group 1 (dcSSc) and group 2 (lcSSC) had similar 10-year survival rates ( $87 \%$ in both groups). This is consistent with results reported in the recent literature, with published 10-year survival rates of $93 \%$ in a Spanish study [4], $82 \%$ in a Canadian study [38], and $88 \%$ in an Italian study [39]. Earlier studies reported poorer 10-year survival rates, of 55\% [40] and 54-67\% [41].

In a Kaplan-Meier-analysis of our cohort according to pulmonary involvement, there was no significant difference for survival in patients with extensive or limited ILD compared with patients without ILD. However, Cox regression demonstrated a significantly higher risk of mortality in patients with extensive disease, compared with those without ILD (hazard ratio $=2.5 ; p=0.04$ ). This is in line with other published studies, which have shown significantly better survival rates in patients with moderate interstitial disease $[16,42]$ than in those with more extensive lung involvement, and with a metaanalysis that found the degree of interstitial changes to be an independent prognostic variable for mortality in SSc [43]. A recent study differentiated among subforms of ILD and showed that manifestation as usual interstitial pneumonia (UIP) has a 2.3-fold risk of mortality compared to manifestation as non-specific interstitial pneumonia (NSIP) [44]. Moreover, new drugs - rituximab [45, 46], mycophenolate [47], their combination [48], and nintedanib [49] - have the potential to provide an effective therapy for ILD. These therapies have been shown to improve parameters of pulmonary function that are related to prognosis, such as DLCO, DLCO/ FVC and TLC [45, 50, 51], but to date no study has actually demonstrated improved survival in patients treated with immunosuppressive agents. Hence, there is a need for new parameters that better predict long time survival under immunosuppression [52].

Our analyses of subgroups as ILD/non-ILD and RHC/ non-RHC found no relevant prognostic differences regarding CPET parameters. This might be caused by the heterogeneity of these groups or by a pre-selection bias. All study centres assessed CPET parameters as indication criteria for the performance of the RHC, and therefore nearly all CPET parameters were worse in the RHC group than in the non-RHC group (e.g. lower peakVO $\mathrm{V}_{2}$ and higher $\mathrm{VE} / \mathrm{VCO}_{2}$-slope). Similarly, the proportion of RHC in ILD was $84 \%$, compared with $54 \%$ in non-ILD patients, preventing an evaluation of prognosis in these subgroups.

In accordance with the literature $[53,54]$ survival in our study was worse in patients with $\mathrm{PH}$ than among patients without $\mathrm{PH}$. Multiple studies have shown that the prognosis of patients with ILD in addition to $\mathrm{PH}$ is even worse than in patients with $\mathrm{PH}$ alone (see Additional file 3: Table S3) [55-59]. It is notable that patients with $\mathrm{PH}$ who have 
Table 3 Cox regression adjusted for age and gender

\begin{tabular}{|c|c|c|c|}
\hline Parameter & Hazard ratio & 95\% confidence interval & $p$-value (bold: $p<0.05$ ) \\
\hline \multicolumn{4}{|l|}{ Demography } \\
\hline age & 1.07 & $1.02 ; 1.11$ & 0.002 \\
\hline female & 0.54 & $0.23 ; 1.27$ & \\
\hline ex-smoker & 2.80 & $0.77 ; 10.14$ & 0.117 \\
\hline smoker & 1.24 & $0.38 ; 4.04$ & 0.724 \\
\hline Charlson index & 1.41 & $1.16 ; 1.72$ & 0.001 \\
\hline body height & 0.98 & $0.93 ; 1.05$ & 0.633 \\
\hline body weight & 0.96 & $0.93 ; 0.99$ & 0.024 \\
\hline BMI & 0.88 & $0.79 ; 0.98$ & 0.019 \\
\hline limited pulmonary manifestation & 0.70 & $0.26 ; 1.94$ & 0.497 \\
\hline extensive pulmonary manifestation & 2.50 & $1.04 ; 6.00$ & 0.040 \\
\hline \multicolumn{4}{|l|}{ Echocardiography } \\
\hline $\mathrm{RV}_{\text {sys }}$ & 1.03 & $1.02 ; 1.05$ & 0.001 \\
\hline \multicolumn{4}{|l|}{ Right heart catheterisation } \\
\hline $\mathrm{RAP}_{\text {mean }}$ & 1.09 & $0.95 ; 1.24$ & 0.200 \\
\hline $\mathrm{PAP}_{\text {mean }}$ & 1.04 & $1.01 ; 1.07$ & 0.002 \\
\hline $\mathrm{PAP}_{\text {mean }} \geq 25 \mathrm{mmHg}$ & 3.67 & $1.54 ; 8.75$ & 0.003 \\
\hline PAWP & 1.05 & $0.95 ; 1.15$ & 0.347 \\
\hline PVR & 1.22 & $1.11 ; 1.34$ & 0.001 \\
\hline Cardiac output & 0.45 & $0.28 ; 0.73$ & 0.001 \\
\hline $\mathrm{PAH}$ & 2.92 & $1.26 ; 6.75$ & 0.012 \\
\hline \multicolumn{4}{|l|}{ Pulmonary function } \\
\hline TLC & 0.97 & $0.96 ; 0.99$ & 0.006 \\
\hline VC (\% pred.) & 0.96 & $0.95 ; 0.98$ & $<0.001$ \\
\hline FVC (\% pred.) & 0.97 & $0.96 ; 0.99$ & 0.001 \\
\hline proportion of patients $\leq 70 \%$ predicted FVC & 4.45 & $1.91 ; 10.35$ & 0.001 \\
\hline FEV1 (\% pred.) & 0.98 & $0.96 ; 0.99$ & 0.005 \\
\hline FEV1/FVC (\%) & 1.02 & $0.98 ; 1.06$ & 0.241 \\
\hline RV (\% pred.) & 1.00 & $0.99 ; 1.01$ & 0.451 \\
\hline RV/TLC (\% pred.) & 1.01 & $0.99 ; 1.04$ & 0.189 \\
\hline DLCO (\% pred.) & 0.94 & $0.91 ; 0.96$ & $<0.001$ \\
\hline proportion of patients $\leq 60 \%$ predicted DLCO & 9.89 & $2.86 ; 34.19$ & $<0.001$ \\
\hline KCO (\% pred.) & 0.95 & $0.93 ; 0.97$ & $<0.001$ \\
\hline FVC (\% pred.)/DLCO (\% pred.) & 2.25 & $1.49 ; 3.41$ & $<0.001$ \\
\hline 6-MWD & 0.991 & $0.986 ; 0.997$ & 0.003 \\
\hline \multicolumn{4}{|l|}{ CPET } \\
\hline maximum power in Watts & 0.95 & $0.94 ; 0.97$ & 0.001 \\
\hline maximum power (\% pred.) & 0.96 & $0.95 ; 0.98$ & $<0.001$ \\
\hline $\mathrm{VO}_{2} @ \mathrm{AT}$ in \% of peakVO 2 predicted & 0.99 & $0.97 ; 1.01$ & 0.346 \\
\hline peakVO & 0.80 & $0.73 ; 0.88$ & $<0.001$ \\
\hline peakVO 2 (\% pred.) & 0.94 & $0.92 ; 0.96$ & $<0.001$ \\
\hline $\mathrm{VO}_{2} / \mathrm{HR}$ & 0.63 & $0.52 ; 0.75$ & $<0.001$ \\
\hline VENCOO ${ }_{2}$-slope & 1.06 & $1.04 ; 1.09$ & $<0.001$ \\
\hline VENCO ${ }_{2} @$ rest & 1.06 & $1.02 ; 1.10$ & 0.003 \\
\hline
\end{tabular}


Table 3 Cox regression adjusted for age and gender (Continued)

\begin{tabular}{llll}
\hline Parameter & Hazard ratio & $95 \%$ confidence interval & $p$-value (bold: $p<0.05)$ \\
\hline VENCO & 1.06 & $1.03 ; 1.09$ & $<\mathbf{0 . 0 0 1}$ \\
Pet $_{2} \mathrm{CO}_{2} @$ rest & 0.88 & $0.81 ; 0.95$ & $\mathbf{0 . 0 0 1}$ \\
Pet $_{\mathrm{CO}} @ \mathrm{AT}$ & 0.86 & $0.81 ; 0.92$ & $<\mathbf{0 . 0 0 1}$ \\
VE/MW (\%) & 1.01 & $0.98 ; 1.03$ & 0.561 \\
VE/MW $>80 \%$ & 1.43 & $0.42 ; 4.79$ & 0.566
\end{tabular}

6-MWD Walking distance in 6 min, BMI Body mass index, CPET Cardiopulmonary exercise testing, DLCO Diffusion capacity of carbon monoxide, FEV1 Forced expiratory volume in 1 second, FVC Forced vital capacity, KCO Krogh factor (DLCO per alveolar volume), ICSSC limited cutaneous manifestation, PAH Pulmonary arterial hypertension, $P A P_{\text {mean }}$ Mean pulmonary arterial pressure (by right heart catheter), $P A W P$ Pulmonary artery wedge pressure, peakVO 2 peak oxygen uptake, $p_{e t} \mathrm{CO}_{2}$ End tidal pressure of carbon dioxide, $p_{e t} \mathrm{CO}_{2} @ A T$ End tidal pressure of carbon dioxide at anaerobic threshold, pred. predicted, PVR Pulmonary vascular resistance, $R A P_{\text {mean }}$ mean right atrial pressure, $R V$ Residual volume, $R V_{\text {sys }}$ Right ventricular systolic pressure (by echocardiography), TLC Total lung capacity, $V C V i t a l$ capacity, VE/MVV Ratio of ventilation to maximum voluntary ventilation, VE/VCO ${ }_{2} @ A T$ ratio of ventilation to carbon dioxide output at anaerobic threshold, VE/ VCO @rest ratio of ventilation to carbon dioxide output at rest, VEN $\mathrm{CO}_{2}$-slope slope of the relation between ventilation and carbon dioxide output, $V \mathrm{O}_{2} @ A T$ oxygen uptake at anaerobic threshold, $\mathrm{VO}_{2} / \mathrm{HR}$ Ratio of oxygen uptake to heart rate

SSc do not often suffer from PAH, but rather from $\mathrm{PH}$ due to left heart disease or PH due to lung disease (groups 1,2 and 3 of the Nice classification, respectively) [31].

Our study has confirmed the prognostic significance of age, gender and pulmonary function parameters (vital capacity, TLC, FVC, FEV1, KCO, DLCO and quotient FVC/DLCO). Studies of these prognostic parameters, as well as meta-analyses describing patients with SSc with and without $\mathrm{PH}$, have been reported previously $[43,60]$. In particular, impaired DLCO and increased FVC/DLCO have a high sensitivity for predicting $\mathrm{PH}$ (particularly $\mathrm{PAH}$ ) and have been included in several screening algorithms for PH in SSc [61-63].

In addition to these established parameters, our study showed a significant relationship between 6-MWD and survival in SSc. To our knowledge, this relationship has not previously been reported. The 6-MWD predicts prognosis in PAH [64], but has several limitations [65, 66]. In general, the use of 6-MWD in studies assessing pulmonary haemodynamics in patients with SSc has been recommended [67], but CPET is regarded as an alternative [68]. The weak correlation between 6-MWD and peak $\mathrm{VO}_{2}$ in our study may indicate that these two parameters identify different patients at risk. Previous 6-MWD studies have assessed subgroups of SSc. A recent meta-analysis of 6-MWD showed differences in walking distances between groups with or without PH or ILD [69]. For the subgroup of patients with SSc and ILD, the 6-MWD has been included in an algorithm for calculating mortality risk [70]. Similarly, in a meta-analysis of patients with SSc with $\mathrm{PH}$, a shorter 6-MWD was associated with a worse prognosis [53], alongside age, gender, pericardial effusion, increased right atrial pressure, increased $\mathrm{PAP}_{\text {mean }}$, and reduced cardiac output. In contrast to our results, a retrospective study by Le Pavec et al. found no relationship between 6MWD and survival in 70 patients with SSc with ILD and $\mathrm{PH}$ [71]. However, Zhao et al. found a 6-MWD of $<380 \mathrm{~m}$ to be an independent predictor of mortality in 190 patients with $\mathrm{PH}$ associated with various collagenoses [72]. This is consistent with our observations, and the

Table 4 Two different models for the calculation of predictive variables for survival

\begin{tabular}{|c|c|c|c|c|c|}
\hline Mortality & Hazard ratio & $p$-value & 95\% Confidence interval & Harrell's C & $\mathrm{N}$ \\
\hline Model 1 & & & & 0.96 & 148 \\
\hline Age & 1.163 & 0.000 & $1070 ; 1264$ & & \\
\hline $\mathrm{KCO}$ & 0.947 & 0.003 & $0.915 ; 0.981$ & & \\
\hline PeakVO $_{2}(\mathrm{ml} / \mathrm{kg} / \mathrm{min})$ & 0.653 & 0.000 & $0.529 ; 0.806$ & & \\
\hline FVC & 0.942 & 0.000 & $0.913 ; 0.973$ & & \\
\hline Model 2 & & & & 0.95 & 150 \\
\hline Age & 1.272 & 0.000 & $1.143 ; 1.416$ & & \\
\hline VENCO ${ }_{2}$-slope & 0.900 & 0.018 & $0.825 ; 0.982$ & & \\
\hline $\mathrm{KCO}$ & 0.918 & 0.008 & $0.862 ; 0.978$ & & \\
\hline FVC & 0.909 & 0.000 & $0.863 ; 0.957$ & & \\
\hline $\mathrm{PeakVO}_{2}$ (\% pred.) & 0.869 & 0.000 & $0.807 ; 0.937$ & & \\
\hline
\end{tabular}

FVC Forced vital capacity, KCO Krogh factor (DLCO per alveolar volume), peakVO 2 peak oxygen uptake, pred. predicted, VE/VCO ${ }_{2}$-slope slope of the relationship between ventilation and carbon dioxide output 

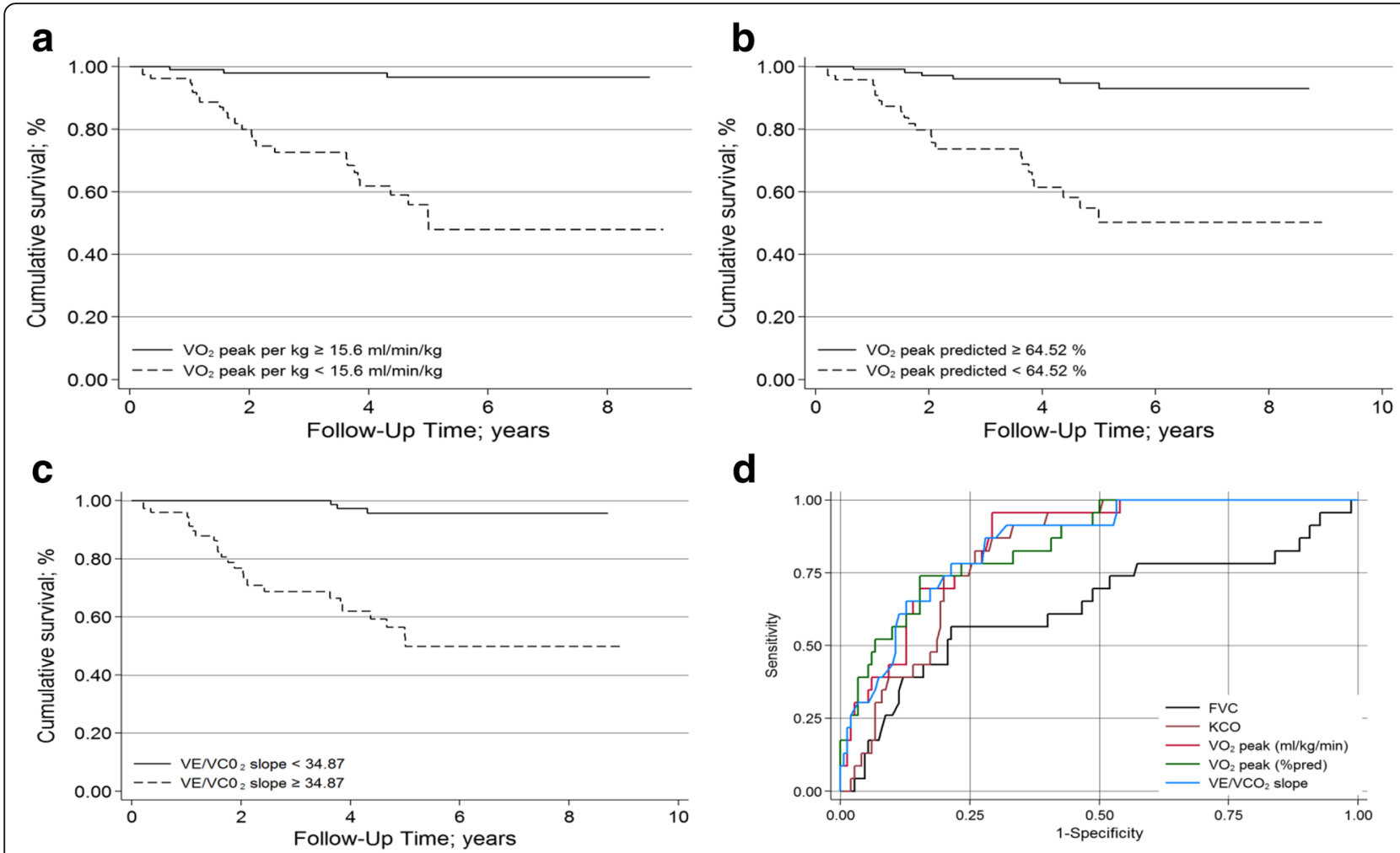

d

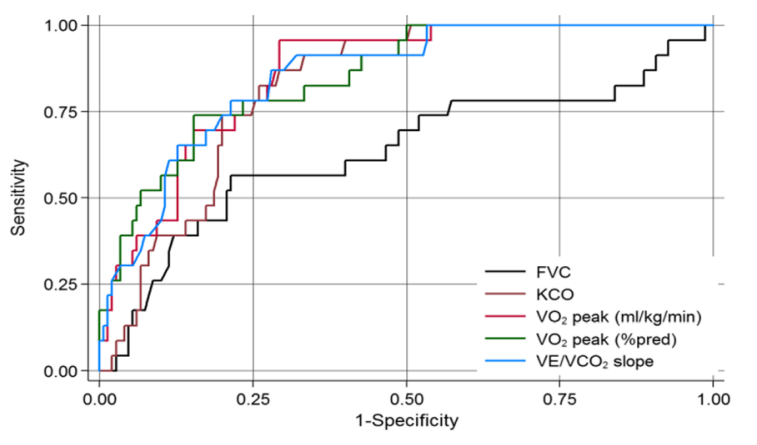

Fig. 2 Survival and CPET parameters, Kaplan-Meier analysis (a-c), receiver operation characteristic. d. a peakVO2 in $\mathrm{mL} \cdot \mathrm{kg}-1 \cdot \mathrm{min}-1$. b peakVO2 as $\%$ of predicted normal value. c VENCO2-slope. d Receiver operation characteristic for selected parameters. FVC: forced vital capacity in \% predicted (area under curve $[A \cup C]=0.73$; best cut-off [cut] $=80 \%$, Youden Index $[Y]=0.30$ ); KCO: Krogh factor (DLCO per alveolar volume in \% predicted; $A \cup C=0.80$, cut=62\%, Y=0.54); peakVO2: peak oxygen uptake in $\mathrm{mL} \cdot \mathrm{kg}-1 \cdot \mathrm{min}-1$ ( $A \cup C=0.8, \mathrm{cut}=15.6, \mathrm{Y}=0.59$ ); VENCO2-slope: slope of the relationship between ventilation and carbon dioxide output ( $A \cup C=0.8$, cut $=35, Y=0.57$ )

difference from our cut-off value of $<430 \mathrm{~m}$ may result from our restricting the population to patients diagnosed with SSc, with or without $\mathrm{PH}$.

The most important insight from our study may be the high prognostic relevance of CPET parameters for the survival of patients with SSc. The results confirm our hypothesis that peakVO $\mathrm{V}_{2}$ and $\mathrm{VE} / \mathrm{VCO}_{2}$-slope can predict survival. In addition, our study found this prognostic relationship in a cohort of patients of whom only a minority had $\mathrm{PH}$ or $\mathrm{PAH}$. This is in contrast to previous studies, which have shown a prognostic relevance for CPET parameters only in patients with SSc who have PH or PAH [12, 13]. Multiple studies, including two analyses of patients with idiopathic $\mathrm{PAH}$ from our study group, have found peakVO $\mathrm{V}_{2}$ and VE/ $\mathrm{VCO}_{2}$-slope, among other parameters, to be related to survival $[12,13,73,74]$. In a recent study of 226 patients with idiopathic PAH, peakVO $, \mathrm{VO}_{2} @ \mathrm{AT}, \mathrm{VO}_{2}$ /heart rate, pet$\mathrm{CO}_{2} @$ rest, $\mathrm{pet}_{\mathrm{et}} \mathrm{CO}_{2} @ \mathrm{AT}, \mathrm{VE} / \mathrm{VCO}_{2}$-slope and VE/ $/ \mathrm{VCO}_{2} @ \mathrm{r}-$ est were related to survival in a univariate analysis (in a multivariate analysis only peakVO $\mathrm{V}_{2}$ and $\mathrm{VE} / \mathrm{VCO}_{2} @$ rest were retained) [74]. Interestingly, CPET parameters can be sensitive in cases of pulmonary vasculopathy without manifested PH or PAH $[10,75,76]$, because in these cases the integration of different cardiac, muscle and pulmonary pathologies in CPET parameters allows prognostication. Moreover, CPET can differentiate between predominantly cardiac and predominantly pulmonary manifestation, and increase the pre-test probability for PH [77]. In this way CPET may suggest specific therapeutic options.

\section{Limitations}

Our retrospective study analysed a prevalent cohort of patients with SSc. The cohort was heterogeneous with respect to pulmonary pressure, ILD, and co-morbidities, which previous studies have found to affect the magnitude of changes in CPET parameters [32, 77, 78]. Although combined from six centres, the number of patients in our study was not high enough to separately analyse patients with $\mathrm{PH}$ and PAH. A slightly different CPET protocol was used in one centre, but this did not change the relevant CPET parameters [79]. However, despite substantial heterogeneity, we were able to identify highly significant prognosticators of survival which suggests robust results.

\section{Conclusions}

Our study has demonstrated the prognostic value of the CPET parameters peakVO $\mathrm{VO}_{2}$ and $\mathrm{VE} / \mathrm{VCO}_{2}$-slope in a 
large cohort of patients with SSc. Cut-off values of peak $\mathrm{VO}_{2}<15.6 \mathrm{~mL} \cdot \mathrm{kg}^{-1} \cdot \mathrm{min}^{-1} \quad(<64.5 \%$ of predicted $)$ and $\mathrm{VE} / \mathrm{VCO}_{2}$-slope $>35$ predict worse survival. Further work is needed to determine whether the poor prognosis in these groups reflects the development of $\mathrm{PH}$. If so, this would be of clinical importance, because while there is no specific SSc therapy, there are therapeutic options for the subgroup with $\mathrm{PH}$. Therefore, peakVO $\mathrm{V}_{2}$ or $\mathrm{VE} / \mathrm{VCO}_{2}-$ slope may increase the pre-test probability for $\mathrm{PH}$, meaning that CPET results may suggest specific treatment.

\section{Supplementary information}

Supplementary information accompanies this paper at https://doi.org/10. 1186/s12890-019-1003-7.

Additional file 1: Table S1 Demographic data in patients with and without right heart catheterization

Additional file 2: Table S2 Demographic parameters in patients with and without ILD

Additional file 3: Table S3 Cardiopulmonary exercise testing and prognostic parameters in SSC

\begin{abstract}
Abbreviations
$\Delta \mathrm{VO}_{2} / \mathrm{HR}$ : Difference between ratio of oxygen uptake / heart rate at rest and atmaximum exercise; 6-MWD: 6-min-walking distance; 6-MWT: 6-min-walk test; AHA: American Heart Association; AT: Anaerobic threshold; ATS: American Thoracic Society; BMI: Body mass index; Cl: Confidence interval; CPET: Cardiopulmonary exercise testing; CREST: Calcinosis, Raynaud's syndrome, Oesophageal dysmotility, Sclerodactyly, Telangiectasia; dcSSc: Disseminated cutaneous SSc; DLCO: Diffusion capacity of carbon monoxide; ERS: European Respiratory Society; ESC: European Society of Cardiology; FEV1: Forced expiratory volume in one second; FVC: Forced vital capacity; HR: Heart rate; HR-CT: High-resolution computed tomography; ILD: Interstitial lung disease; IQR: Interquartile range; KCO: Krogh factor (DLCO per alveolar volume); IcSSc: SSc with limited cutaneous manifestation; LVEF: Left ventricular ejection fraction; NSIP: Non-specific interstitial pneumonia; PAH: Pulmonary arterial hypertension; PAP mean: Mean pulmonary arterial pressure (by right heart catheterization); PAWP: Pulmonary artery wedge pressure; peakVO $\mathrm{O}_{2}$ : Peak oxygen uptake; $\mathrm{pet}_{\mathrm{et}} \mathrm{CO}_{2}$ : End tidal pressure of carbon dioxide; $\mathrm{p}_{\mathrm{et}} \mathrm{CO}_{2} @ \mathrm{AT}$ : End tidal pressure of carbon dioxide at anaerobic threshold; PH: Pulmonary hypertension; PVR: Pulmonary vascular resistance; $\mathrm{RAP}_{\text {mea: }}$ Mean right atrial pressure (by right heart catheterization); RHC: Right heart catheterization; ROC: Receiver operating characteristic; $\mathrm{RV}$ : Residual volume; $\mathrm{RV}_{\text {sys: }}$ : Right ventricular systolic pressure (by echocardiography); SD: Standard deviation; SSC: Systemic sclerosis; TLC: Total lung capacity; TR: Tricuspid regurgitation; UIP: Usual interstitial pneumonia; VE/MW: Ratio of ventilation to maximum voluntary ventilation; VE/ VCO $@ @ A T$ : Ratio of ventilation to carbon dioxide output at anaerobic threshold; VENCO $@$ @rest: Ratio of ventilation to carbon dioxide output at rest; $V E / \mathrm{NCO}_{2}$-slope: Slope of the relation between ventilation and carbon dioxide output; $\mathrm{VO}_{2} / \mathrm{HR}$ : Oxygen uptake per heart rate; VO $\mathrm{O}_{2} @ \mathrm{AT}$ : Oxygen uptake at anaerobic threshold
\end{abstract}

\section{Acknowledgements}

For the current manuscript, editorial assistance was provided by Dr. Paul Overton (Beacon Medical Communications Ltd., Brighton, UK), funded by the University of Greifswald.

\section{Authors' contributions}

RE initiated and coordinated the study, and takes responsibility for the integrity of the data and the accuracy of the data analysis, TI provided the statistical analysis and interpretation. GK, JW, MHa, MHe, RE, HO, GK, TL and SG assessed the patients at their institutions and participated in the design of the study. DH conceived the study, and RE and DH wrote the manuscript. All authors read and approved the final manuscript.

\section{Funding}

No funding was obtained for this study.

\section{Availability of data and materials}

The database used to calculate the mortality and prognostic factors can be made available on request by Prof. Ralf Ewert via ralf.ewert@med.unigreifswald.de. Availability of data from the participating six sites, however, might be limited by the patients' consent and should be determined on a case-by-case basis

\section{Ethics approval and consent to participate}

The study was approved by the ethics committee of Greifswald University (No. 043/13a, study protocol and amendment of May 5th, 2015). Our study was a retrospective analysis of patients with SSc from a prevalent cohort. This was not a healthcare intervention trial. The data were analysed with the informed, written consent of all patients.

\section{Consent for publication}

The manuscript does not contain data from any individual person in any form.

\section{Competing interests}

GK: personal fees and non-financial support from Actelion, Bayer, GSK, MSD, Pfizer, AOP, Boehringer Ingelheim, Novartis, Chiesi

$\mathrm{DH}$, JW and Tl: none

MHe: research funding and grant from Actelion; honoraria for lectures from Actelion, Bayer Healthcare, Berlin Chemie, Boehringer Ingelheim, Daichii Sankyo, GSK, MSD, Novartis, Pfizer; participation in clinical trials from Actelion, Bayer, GSK, Pfizer, United Therapeutics; Honoraria for Advisory Boards from Actelion, Bayer, Boehringer, GSK, MSD

HO: grants from Actelion, Boehringer, MSD, Inventiva; personal fees from Actelion, Bayer, Boehringer, Chiesi, GSK, Menarini, MSD; non-financial support from Actelion, Bayer, Boehringer, GSK, Menarini, MSD

SG: personal fees from Boehringer, Roche, Novartis, Berlin Chemie; nonfinancial support from Actelion

MHa: personal fees and non-financial support from Actelion, Bayer, GSK, MSD, Novartis, Berlin Chemie, OMT, Astra

RE: Grant and lecture fee from Actelion; grants from United Therapeutics, OMT, Boehringer; personal fees from Actelion, Bayer, Novartis, Teva, OMT, Astra, Boehringer, United Therapeutics TL:

Grant, personal fees and non-financial support from Actelion, Bayer, GSK and Pfizer, personal fees and non-financial support from AOP and MSD, grant and personal fee from United Therapeutics.

\section{Author details}

${ }^{1}$ Department of Internal Medicine, University Greifswald, Greifswald, Germany. ${ }^{2}$ Institute for Community Medicine, University Greifswald, Greifswald, Germany. ${ }^{3}$ Department of Cardiology, DRK Kliniken Berlin, Berlin, Germany. ${ }^{4}$ Missio Clinic, Würzburg, Germany. ${ }^{5}$ Department of Internal Medicine II, University Medical Center Regensburg, Regensburg, Germany. ${ }^{6}$ Department of Internal Medicine I, University Hospital of TU Dresden, Dresden, Germany. 'PSL Pulmonary Study Center, Leipzig, Germany. ${ }^{8}$ Department of Internal Medicine, Vivantes Kliniken Berlin, Spandau, Germany. ${ }^{9}$ Department of Internal Medicine, Medical University of Graz, Division of Pulmonology, Graz, Austria. ${ }^{10}$ Ludwig Boltzmann Institute for Lung Vascular Research, Graz, Austria.

Received: 13 April 2019 Accepted: 20 November 2019 Published online: 29 November 2019

\section{References}

1. Arias-Nunez MC, Llorca J, Vazquez-Rodriguez TR, Gomez-Acebo I, MirandaFilloy JA, Martin J, Gonzalez-Juanatey C, Gonzalez-Gay MA. Systemic sclerosis in northwestern Spain: a 19-year epidemiologic study. Medicine (Baltimore). 2008;87(5):272-80.

2. Hunzelmann N, Krieg T, der Kooperationspartner D. The German network for systemic sclerosis (DNSS): current data on diagnostics and therapy. Hautarzt. 2012;63(S1):71-5. 
3. Galluccio F, Walker UA, Nihtyanova S, Moinzadeh P, Hunzelmann N, Krieg T, Steen V, Baron M, Sampaio-Barros P, Kayser C, et al. Registries in systemic sclerosis: a worldwide experience. Rheumatology (Oxford). 2011;50(1):60-8.

4. Simeon-Aznar CP, Fonollosa-Pla V, Tolosa-Vilella C, Espinosa-Garriga G, Campillo-Grau M, Ramos-Casals M, Garcia-Hernandez FJ, Castillo-Palma MJ, Sanchez-Roman J, Callejas-Rubio JL, et al. Registry of the Spanish network for systemic sclerosis: survival, prognostic factors, and causes of death. Medicine (Baltimore). 2015;94(43):e1728.

5. Solomon JJ, Olson AL, Fischer A, Bull T, Brown KK, Raghu G. Scleroderma lung disease. Eur Respir Rev. 2013;22(127):6-19.

6. Tyndall AJ, Bannert B, Vonk M, Airo P, Cozzi F, Carreira PE, Bancel DF, Allanore Y, Muller-Ladner U, Distler $O$, et al. Causes and risk factors for death in systemic sclerosis: a study from the EULAR scleroderma trials and research (EUSTAR) database. Ann Rheum Dis. 2010;69(10):1809-15.

7. Elhai M, Meune C, Avouac J, Kahan A, Allanore Y. Trends in mortality in patients with systemic sclerosis over 40 years: a systematic review and meta-analysis of cohort studies. Rheumatology (Oxford). 2012;51(6):1017-26.

8. Cuomo G, Santoriello C, Polverino F, Ruocco L, Valentini G, Polverino M. Impaired exercise performance in systemic sclerosis and its clinical correlations. Scand J Rheumatol. 2010;39(4):330-5.

9. Rosato E, Romaniello A, Magri D, Bonini M, Sardo L, Gigante A, Quarta S, Digiulio MA, Viola G, Di Paolo M, et al. Exercise tolerance in systemic sclerosis patients without pulmonary impairment: correlation with clinical variables. Clin Exp Rheumatol. 2014;32(6 Suppl 86):S-103-8.

10. Boutou AK, Pitsiou GG, Siakka P, Dimitroulas T, Paspala A, Sourla E, Chavouzis N, Garyfallos A, Argyropoulou P, Stanopoulos I. Phenotyping exercise limitation in systemic sclerosis: the use of cardiopulmonary exercise testing. Respiration. 2016;91(2):115-23.

11. Walkey AJ, leong M, Alikhan M, Farber HW. Cardiopulmonary exercise testing with right-heart catheterization in patients with systemic sclerosis. J Rheumatol. 2010;37(9):1871-7.

12. Groepenhoff H, Vonk-Noordegraaf A, Boonstra A, Spreeuwenberg MD, Postmus PE, Bogaard $\mathrm{HJ}$. Exercise testing to estimate survival in pulmonary hypertension. Med Sci Sports Exerc. 2008;40(10):1725-32.

13. Deboeck G, Scoditti C, Huez S, Vachiery JL, Lamotte M, Sharples L, Melot C, Naeije R. Exercise testing to predict outcome in idiopathic versus associated pulmonary arterial hypertension. Eur Respir J. 2012;40(6):1410-9.

14. Knobler R, Moinzadeh P, Hunzelmann N, Kreuter A, Cozzio A, Mouthon L, Cutolo M, Rongioletti F, Denton CP, Rudnicka L, et al. European dermatology forum S1-guideline on the diagnosis and treatment of sclerosing diseases of the skin, part 1: localized scleroderma, systemic sclerosis and overlap syndromes. J Eur Acad Dermatol Venereol. 2017;31(9):1401-24.

15. van den Hoogen F, Khanna D, Fransen J, Johnson SR, Baron M, Tyndall A, Matucci-Cerinic M, Naden RP, Medsger TA Jr, Carreira PE, et al. 2013 classification criteria for systemic sclerosis: an American college of rheumatology/European league against rheumatism collaborative initiative. Ann Rheum Dis. 2013;72(11):1747-55

16. Goh NS, Desai SR, Veeraraghavan S, Hansell DM, Copley SJ, Maher TM, Corte TJ, Sander CR, Ratoff J, Devaraj A, et al. Interstitial lung disease in systemic sclerosis: a simple staging system. Am J Respir Crit Care Med. 2008;177(11):1248-54.

17. Charlson ME, Pompei P, Ales KL, MacKenzie CR. A new method of classifying prognostic comorbidity in longitudinal studies: development and validation. J Chronic Dis. 1987;40(5):373-83.

18. Lang RM, Badano LP, Mor-Avi V, Afilalo J, Armstrong A, Ernande L, Flachskampf FA, Foster E, Goldstein SA, Kuznetsova T, et al. Recommendations for cardiac chamber quantification by echocardiography in adults: an update from the American Society of Echocardiography and the European Association of Cardiovascular Imaging. Eur Heart J Cardiovasc Imaging. 2015;16(3):233-70.

19. Weihs W. Die standardisierte Echokardiographie: Durchführung, Archivierung und Befunderstellung inkl. Evaluierung der systolischen Linksventrikelfunktion. J Für Kardiologie - Aust J Cardiol. 2014;21(1-2):8-13.

20. Macintyre N, Crapo RO, Viegi G, Johnson DC, van der Grinten CP, Brusasco $V$, Burgos F, Casaburi R, Coates A, Enright P, et al. Standardisation of the single-breath determination of carbon monoxide uptake in the lung. Eur Respir J. 2005;26(4):720-35.

21. Miller MR, Hankinson J, Brusasco V, Burgos F, Casaburi R, Coates A, Crapo R, Enright $P$, van der Grinten CP, Gustafsson P, et al. Standardisation of spirometry. Eur Respir J. 2005;26(2):319-38.

22. Wanger J, Clausen JL, Coates A, Pedersen OF, Brusasco V, Burgos F, Casaburi $R$, Crapo $R$, Enright $P$, van der Grinten $C P$, et al. Standardisation of the measurement of lung volumes. Eur Respir J. 2005;26(3):511-22.
23. Glaser S, Ittermann T, Schaper C, Obst A, Dorr M, Spielhagen T, Felix SB, Volzke H, Bollmann T, Opitz CF, et al. The study of health in Pomerania (SHIP) reference values for cardiopulmonary exercise testing. Pneumologie. 2013;67(1):58-63.

24. Koch B, Friedrich N, Volzke H, Jorres RA, Felix SB, Ewert R, Schaper C, Glaser $S$. Static lung volumes and airway resistance reference values in healthy adults. Respirology. 2013;18(1):170-8.

25. Koch B, Schaper C, Ittermann T, Volzke H, Felix SB, Ewert R, Glaser S. Reference values for lung function testing in adults--results from the study of health in Pomerania (SHIP). Dtsch Med Wochenschr. 2009;134(46):2327-32.

26. Cotes JE, Chinn DJ, Quanjer PH, Roca J, Yernault JC. Standardization of the measurement of transfer factor (diffusing capacity). Eur Respir J. 1993;6 Suppl 16(Suppl 16):41-52.

27. Glaser S, Koch B, Ittermann T, Schaper C, Dorr M, Felix SB, Volzke H, Ewert R, Hansen JE. Influence of age, sex, body size, smoking, and beta blockade on key gas exchange exercise parameters in an adult population. Eur J Cardiovasc Prev Rehabil. 2010;17(4):469-76.

28. ATS Committee on Proficiency Standards for Clinical Pulmonary Function Laboratories. ATS statement: guidelines for the six-minute walk test. Am J Respir Crit Care Med. 2002;166(1):111-7.

29. Rosenkranz S, Behr J, Ewert R, Ghofrani HA, Grunig E, Halank M, Hoeper MM, Leuchte $\mathrm{HH}$, Olschewski H. Schmeisser a et al: [right heart catheterization in pulmonary hypertension]. Dtsch Med Wochenschr. 2011;136(50):2601-16 quiz 2617-2620.

30. Avouac J, Huscher D, Furst DE, Opitz CF, Distler O, Allanore Y. Expert consensus for performing right heart catheterisation for suspected pulmonary arterial hypertension in systemic sclerosis: a Delphi consensus study with cluster analysis. Ann Rheum Dis. 2014;73(1):191-7.

31. Galie N, Humbert M, Vachiery JL, Gibbs S, Lang I, Torbicki A, Simonneau G, Peacock A, Vonk Noordegraaf A, Beghetti M, et al. 2015 ESC/ERS Guidelines for the diagnosis and treatment of pulmonary hypertension: The Joint Task Force for the Diagnosis and Treatment of Pulmonary Hypertension of the European Society of Cardiology (ESC) and the European Respiratory Society (ERS): Endorsed by: Association for European Paediatric and Congenital Cardiology (AEPC), International Society for Heart and Lung Transplantation (ISHLT). Eur Heart J. 2016;37(1):67-119.

32. Chia EM, Lau EM, Xuan W, Celermajer DS, Thomas L. Exercise testing can unmask right ventricular dysfunction in systemic sclerosis patients with normal resting pulmonary artery pressure. Int J Cardiol. 2016;204:179-86.

33. de Oliveira NC, dos Santos Sabbag LM, Ueno LM, de Souza RB, Borges CL, de Sa Pinto AL, Lima FR. Reduced exercise capacity in systemic sclerosis patients without pulmonary involvement. Scand J Rheumatol. 2007;36(6):458-61.

34. Hargardottir $\mathrm{H}$, van Helvoort HA, Vonk MC, van den Hoogen FH, Dekhuijzen PN, Heijdra YF. Exercise in systemic sclerosis intensifies systemic inflammation and oxidative stress. Scand J Rheumatol. 2010;39(1):63-70.

35. Plazak W, Gryga K, Sznajd J, Tomkiewicz-Pajak L, Suchon E, Wilisowska J, Musial J, Podolec P. Diastolic heart dysfunction, increased pulmonary capillary wedge pressure and impaired exercise tolerance in patients with systemic sclerosis. Kardiol Pol. 2011;69(3):243-9.

36. Sudduth CD, Strange C, Cook WR, Miller KS, Baumann M, Collop NA, Silver RM. Failure of the circulatory system limits exercise performance in patients with systemic sclerosis. Am J Med. 1993;95(4):413-8.

37. Swigris JJ, Zhou X, Wamboldt FS, du Bois R, Keith R, Fischer A, Cosgrove GP, Frankel SK, Curran-Everett D, Brown KK. Exercise peripheral oxygen saturation (SpO2) accurately reflects arterial oxygen saturation ( $\mathrm{SaO} 2)$ and predicts mortality in systemic sclerosis. Thorax. 2009;64(7):626-30.

38. Al-Dhaher FF, Pope JE, Ouimet JM. Determinants of morbidity and mortality of systemic sclerosis in Canada. Semin Arthritis Rheum. 2010;39(4):269-77.

39. Ferri C, Valentini G, Cozzi F, Sebastiani M, Michelassi C, La Montagna G, Bullo A, Cazzato M, Tirri E, Storino F, et al. Systemic sclerosis. Medicine. 2002;81(2):139-53.

40. Mayes MD, Lacey JV Jr, Beebe-Dimmer J, Gillespie BW, Cooper B, Laing TJ, Schottenfeld D. Prevalence, incidence, survival, and disease characteristics of systemic sclerosis in a large US population. Arthritis Rheum. 2003;48(8):2246-55.

41. Steen VD, Medsger TA. Changes in causes of death in systemic sclerosis, 1972-2002. Ann Rheum Dis. 2007;66(7):940-4.

42. Poormoghim H, Lakeh MM, Mohammadipour M, Talehy-Moineddin S, Sodagari F. Pulmonary survival study in 91 patients with systemic sclerosis. Rheumatol Int. 2011;31(12):1577-82.

43. Winstone TA, Assayag D, Wilcox PG, Dunne JV, Hague CJ, Leipsic J, Collard HR, Ryerson CJ. Predictors of mortality and progression in scleroderma-associated interstitial lung disease: a systematic review. Chest. 2014;146(2):422-36. 
44. Mango RL, Matteson EL, Crowson CS, Ryu JH, Makol A. Assessing mortality models in systemic sclerosis-related interstitial lung disease. Lung. 2018; 196(4):409-16.

45. Thiebaut M, Launay D, Riviere S, Mahevas T, Bellakhal S, Hachulla E, Fain O, Mekinian A. Efficacy and safety of rituximab in systemic sclerosis: French retrospective study and literature review. Autoimmun Rev. 2018;17(6):582-7.

46. Narvaez J, Pirola JP. J LL, Juarez P, Nolla JM, Valenzuela a: effectiveness and safety of rituximab for the treatment of refractory systemic sclerosis associated calcinosis: a case series and systematic review of the literature. Autoimmun Rev. 2019;18(3):262-9.

47. Volkmann ER, Tashkin DP, Li N, Roth MD, Khanna D, Hoffmann-Vold AM, Kim G, Goldin J, Clements PJ, Furst DE, et al. Mycophenolate Mofetil versus placebo for systemic sclerosis-related interstitial lung disease: an analysis of scleroderma lung studies I and II. Arthritis Rheumatol. 2017;69(7):1451-60.

48. Fraticelli P, Fischetti C, Salaffi F, Carotti M, Mattioli M, Pomponio G, Gabrielli A. Combination therapy with rituximab and mycophenolate mofetil in systemic sclerosis. A single-centre case series study. Clin Exp Rheumatol. 2018;36 Suppl 113(4):142-5.

49. Distler O, Highland KB, Gahlemann M, Azuma A, Fischer A, Mayes MD, Raghu G, Sauter W, Girard M, Alves M, et al. Nintedanib for systemic sclerosisassociated interstitial lung disease. N Engl J Med. 2019;380(26):2518-28.

50. Caron M, Hoa S, Hudson M, et al. Pulmonary function tests as outcomes for systemicsclerosis interstitial lung disease. Eur Respir Rev. 2018;27:170102.

51. Barnes H, Holland AE, Westall GP, Goh NS, Glaspole IN. Cyclophosphamide for connective tissue disease-associated interstitial lung disease. Cochrane Database Syst Rev. 2018;1:Cd010908.

52. Kouranos V, Miranda G, Corte TJ, Renzoni EA. New treatment paradigms for connective tissue disease-associated interstitial lung disease. Curr Opin Pulm Med. 2018;24(5):453-60.

53. Lefevre G, Dauchet L, Hachulla E, Montani D, Sobanski V, Lambert M, Hatron PY, Humbert M, Launay D. Survival and prognostic factors in systemic sclerosis-associated pulmonary hypertension: a systematic review and metaanalysis. Arthritis Rheum. 2013;65(9):2412-23.

54. Trad S, Amoura Z, Beigelman C, Haroche J, Costedoat N, le TH B, Cacoub P, Frances $C$, Wechsler B, Grenier $P$, et al. Pulmonary arterial hypertension is a major mortality factor in diffuse systemic sclerosis, independent of interstitial lung disease. Arthritis Rheum. 2006;54(1):184-91.

55. Condliffe R, Kiely DG, Peacock AJ, Corris PA, Gibbs JS, Vrapi F, Das C, Elliot CA, Johnson M, DeSoyza J, et al. Connective tissue disease-associated pulmonary arterial hypertension in the modern treatment era. Am J Respir Crit Care Med. 2009;179(2):151-7.

56. Launay D, Humbert M, Berezne A, Cottin V, Allanore Y, Couderc LJ, Bletry O, Yaici A, Hatron PY, Mouthon L, et al. Clinical characteristics and survival in systemic sclerosis-related pulmonary hypertension associated with interstitial lung disease. Chest. 2011;140(4):1016-24

57. Mathai SC, Hummers LK, Champion HC, Wigley FM, Zaiman A, Hassoun PM, Girgis RE. Survival in pulmonary hypertension associated with the scleroderma spectrum of diseases: impact of interstitial lung disease. Arthritis Rheum. 2009;60(2):569-77.

58. Michelfelder M, Becker M, Riedlinger A, Siegert E, Dromann D, Yu X, Petersen F, Riemekasten $\mathrm{G}$. Interstitial lung disease increases mortality in systemic sclerosis patients with pulmonary arterial hypertension without affecting hemodynamics and exercise capacity. Clin Rheumatol. 2017:36(2):381-90.

59. Volkmann ER, Saggar R, Khanna D, Torres B, Flora A, Yoder L, Clements PJ, Elashoff RM, Ross DJ, Agrawal $\mathrm{H}$, et al. Improved transplant-free survival in patients with systemic sclerosis-associated pulmonary hypertension and interstitial lung disease. Arthritis Rheumatol. 2014;66(7):1900-8.

60. Johnson SR, Swiston JR, Granton JT. Prognostic factors for survival in scleroderma associated pulmonary arterial hypertension. J Rheumatol. 2008; 35(8):1584-90.

61. Coghlan JG, Denton CP, Grunig E, Bonderman D, Distler O, Khanna D, Muller-Ladner U, Pope JE, Vonk MC, Doelberg M, et al. Evidence-based detection of pulmonary arterial hypertension in systemic sclerosis: the DETECT study. Ann Rheum Dis. 2014;73(7):1340-9.

62. Hao Y, Thakkar V, Stevens W, Morrisroe K, Prior D, Rabusa C, Youssef $P$, Gabbay E, Roddy J, Walker J, et al. A comparison of the predictive accuracy of three screening models for pulmonary arterial hypertension in systemic sclerosis. Arthritis Res Ther. 2015;17(1):7.

63. Thakkar V, Stevens WM, Moore OA, Nikpour M. Performance of screening algorithms in systemic sclerosis-related pulmonary arterial hypertension: a systematic review. Intern Med J. 2013;43(7):751-60.
64. Farber HW, Miller DP, McGoon MD, Frost AE, Benton WW, Benza RL. Predicting outcomes in pulmonary arterial hypertension based on the 6minute walk distance. J Heart Lung Transplant. 2015;34(3):362-8.

65. Garin MC, Highland KB, Silver RM, Strange C. Limitations to the 6-minute walk test in interstitial lung disease and pulmonary hypertension in scleroderma. J Rheumatol. 2009;36(2):330-6.

66. Ghosh SK, Corkill MM, Hart HH, Ng KP. Screening for pulmonary arterial hypertension in patients with scleroderma--a New Zealand perspective. N Z Med J. 2014;127(1400):30-8.

67. Distler O, Behrens F, Pittrow D, Huscher D, Denton CP, Foeldvari I, Humbert M, Matucci-Cerinic M, Nash P, Opitz CF, et al. Defining appropriate outcome measures in pulmonary arterial hypertension related to systemic sclerosis: a Delphi consensus study with cluster analysis. Arthritis Rheum. 2008;59(6):867-75.

68. Rizzi M, Radovanovic D, Santus P, Airoldi A, Frassanito F, Vanni S, Cristiano A, Sarzi-Puttini $P$, Atzeni F. Usefulness of six-minute walk test in systemic sclerosis. Clin Exp Rheumatol. 2018;36 Suppl 113(4):161-7.

69. Vandecasteele E, De Pauw M, De Keyser F, Decuman S, Deschepper E, Piette Y, Brusselle G, Smith V. Six-minute walk test in systemic sclerosis: a systematic review and meta-analysis. Int J Cardiol. 2016;212:265-73.

70. Ryerson CJ, O'Connor D, Dunne JV, Schooley F, Hague CJ, Murphy D, Leipsic J, Wilcox PG. Predicting mortality in systemic sclerosis-associated interstitial lung disease using risk prediction models derived from idiopathic pulmonary fibrosis. Chest. 2015;148(5):1268-75.

71. Le Pavec J, Girgis RE, Lechtzin N, Mathai SC, Launay D, Hummers LK, Zaiman A, Sitbon O, Simonneau G, Humbert M, et al. Systemic sclerosis-related pulmonary hypertension associated with interstitial lung disease: impact of pulmonary arterial hypertension therapies. Arthritis Rheum. 2011;63(8):2456-64.

72. Zhao J, Wang Q, Liu Y, Tian Z, Guo X, Wang H, Lai J, Huang C, Yang X, Li M, et al. Clinical characteristics and survival of pulmonary arterial hypertension associated with three major connective tissue diseases: a cohort study in China. Int J Cardiol. 2017;236:432-7.

73. Wensel R, Opitz CF, Anker SD, Winkler J, Hoffken G, Kleber FX, Sharma R, Hummel M, Hetzer R, Ewert R. Assessment of survival in patients with primary pulmonary hypertension: importance of cardiopulmonary exercise testing. Circulation. 2002;106(3):319-24.

74. Wensel R, Francis DP, Meyer FJ, Opitz CF, Bruch L, Halank M, Winkler J, Seyfarth HJ, Glaser S, Blumberg F, et al. Incremental prognostic value of cardiopulmonary exercise testing and resting haemodynamics in pulmonary arterial hypertension. Int J Cardiol. 2013;167(4):1193-8.

75. Dumitrescu D, Oudiz RJ, Karpouzas G, Hovanesyan A, Jayasinghe A, Hansen JE, Rosenkranz S, Wasserman K. Developing pulmonary vasculopathy in systemic sclerosis, detected with non-invasive cardiopulmonary exercise testing. PLoS One. 2010;5(12):e14293.

76. Reichenberger F, Voswinckel R, Schulz R, Mensch O, Ghofrani HA, Olschewski H, Seeger W. Noninvasive detection of early pulmonary vascular dysfunction in scleroderma. Respir Med. 2009;103(11):1713-8.

77. Morelli S, Ferrante L, Sgreccia A, Eleuteri ML, Perrone C, De Marzio P, Balsano F. Pulmonary hypertension is associated with impaired exercise performance in patients with systemic sclerosis. Scand J Rheumatol. 2000; 29(4):236-42.

78. Dumitrescu D, Nagel C, Kovacs G, Bollmann T, Halank M, Winkler J, Hellmich M, Grunig E, Olschewski H, Ewert R, et al. Cardiopulmonary exercise testing for detecting pulmonary arterial hypertension in systemic sclerosis. Heart. 2017;103(10):774-82.

79. Ewert R, Ittermann T, Bollmann T, Spielhagen T, Dorr M, Schaper C, Warnke C, Obst A, Friedrich N, Felix SB, et al. Lung health data of the study of health in Pomerania - a review of samples, methods and first results. Pneumologie. 2017;71(1):17-35.

\section{Publisher's Note}

Springer Nature remains neutral with regard to jurisdictional claims in published maps and institutional affiliations. 